\title{
EMPLOYMENT READINESS AND STUDENT TEACHING PERFORMANCE OF COED SENIORS
}

\author{
Lorna D. Capito \\ ESSU Main Campus, Graduate School, Borongan City, Eastern Samar
}

Article DOI: https://doi.org/10.36713/epra9060

DOI No: 10.36713/epra9060

\begin{abstract}
The study was conducted at the Eastern Samar State University Main Campus during the second semester of the school year 2018 to 2019. It aimed to determine the employment readiness of the respondents in terms of their personal skills; instructional skills; and management skills. It also intended to describe their student teaching performance in terms of their average grade in Student Teaching in the Elem/Sec Schools subject; and to determine whether there is significant relationship between these variables.. Likert-type questionnaire was used to gather data as well as secondary data and employed both Descriptive and Inferential statistics for the analysis of the gathered data..

The findings of the study revealed that the respondents' employment readiness were interpreted as "Much Skilled". It also reflected that $95.6 \%$ or majority of the senior students were excellent in their teaching performance. Further results reflected that there was no significant relationship between employment readiness in terms of personality skills and instructional skills components of the respondents and their student teaching performance but a significant relationship between employment readiness of the respondents in terms of management skills and their student teaching performance.

The results of the study implied that COED senior students are ready for employment and that they have developed the necessary skills for teaching and can excellently practice the techniques, skills, and positive attitudes in teaching in preparation for the real world of teaching profession as reflected in their student teaching performance. These findings also implies that student teachers' skills in managing classroom activities, efficient planning and organizing can highly influence their outlook and preparedness towards the teaching profession .Hence, student teaching curriculum must be enhanced towards improving the management skills of students.
\end{abstract}

KEYWORDS: employment readiness, student teaching performance

\section{INTRODUCTION}

Background of the Study

Teachers hold influence and are a powerful force for equal access to quality education and sustainable global development. However, recruitment of skilled teachers remains preoccupying [1] (en.unesco.org.,2020).

The International Task Force on Teacher for Education 2030 hosted by UNESCO specifically calls out its member states in the Inchon Declaration to ensure that teachers and educators are adequately recruited, welltrained, and professionally qualified. This declaration implies that member states should look into the readiness of teacher applicants prior to their employment [2] (teachersforefa.unesco.org,2020).

As stated in Article XIV Sec.1 of the Philippine Constitution, the state is directed to protect and promote the right of its citizens to quality education at all levels. The state should therefore uphold quality in education by considering the suitability of teacher applicants in terms of their personal, instructional, and management skills as determinants of their employment readiness as pre-service educators.

The College of Education of Eastern Samar State University-Main Campus, being one of the teacher training institutions of the country, engages its student-teachers in practice teaching as the latter is viewed to be an integral part of Teacher Education Program. With practice teaching, student teachers are given the opportunity to practice the techniques, skills, and positive attitudes in teaching in preparation for the real world of teaching profession. Furthermore, the overall teaching performance of student-teachers could influence their outlook and preparedness towards the teaching profession [3](Mannathoko,( 2013).

With the demand of the job market for skilled teacher applicants and with the existing tight job competition, it is but important to look into their student teaching performance. Employment readiness and student teaching performance of student teachers in need to be closely determined as factors of their chances of 
being employed so that the student teaching curriculum can be revised. Hence the conduct of this study to evaluate the relationship of employment readiness and student teaching performance of COED seniors in ESSU Main Campus during the SY 2018-2019 as inputs to curricular revision.

\section{Objectives of the Study}

This investigation aims to evaluate the relationship of employment readiness and student teaching performance of COED Seniors in ESSU Main Campus. Specifically, this study is anchored on addressing the following objectives :

1. To determine the employment readiness of COED seniors in ESSU Main Campus in terms of their :

$1.1 \quad$ Personal Skills

1.2 Instructional Skills

1.3 Management Skills

2. To describe the student teaching performance of COED seniors in ESSU

Main Campus in terms of their average grade in Student Teaching in the

Elem/Sec Schools subject;

3. To determine if there is a significant relationship between the employment readiness of COED seniors and their student teaching performance .

\section{Significance of the Study}

The results and findings of this study may provide relevant insights regarding employment readiness and its relevance to the students' teaching performance of COED seniors in ESSU Main Campus. This study will look forward to delivering valuable inputs to the following:

Teachers - they will get deeper understanding of the diversity of the learning of their pupils, how the employment readiness of the students play a vital role in terms of their learning performance in professional education courses and to take into consideration the level of readiness of their students in the teaching and learning process as well as in curriculum development.

Students - this group of individuals will be able to gain insight on how their employment readiness play a pivotal role in their learning performance in school, and also give them ideas on how to develop their personal, instructional and management skills to improve their learning performance in the professional courses.

Parents - for them to gain significant insights on how employment readiness of their children affect their learning performance in school.

School Administrators- may obtain ideas from this study on how to assist the teachers improve their teaching performance and strategies as well as in curriculum development that would help them deal with the different levels of competency in terms personal, instructional and management skills of the students .

Future Researchers - the findings of this study may provide them vital references in similar studies and may provide essential inputs in the design and pursuit of related researches.

\section{Scope and Delimitation of the Study}

The study was limited to finding the employment readiness and student teaching performance of COED Seniors in ESSU Main Campus during the School Year 2018-2019. This covered all the COED seniors both from the BEED and BSED programs taking up Student Teaching in the Elementary/Secondary Schools subject.

\section{Hypothesis of the Study}

There is no significant relationship between the employment readiness and student teaching performance of COED seniors.

\section{METHODOLOGY}

\section{Research Design}

The study employed the descriptive correlational design which enabled it to satisfy the research objectives. Initially, descriptive approach through survey was employed to gather the pertinent data relevant to the study. A survey is a descriptive type of research design used when the researcher intends to provide a quantitative or numeric description of trends, attitudes, opinions of a population by studying a sample of that population [4](Cresswell, J.W., 2013). The researcher gathered information through survey the employment readiness of the respondents and through secondary data their student teaching performance in terms of their average grade in Student Teaching in the Elem/Sec Schools subject. This study then used the correlational design to examine if there is a significant relationship between the employment readiness and student teaching 
performance of COED seniors in ESSU Main Campus. A test for validity and reliability was run to check for consistency of measures used in the research instrument.

\section{Locale of the Study}

The study was conducted at the Eastern Samar State University Main Campus.

Senior students from both the BEED and BSED programs were involved in this study.

\section{Respondents of the Study}

The study was participated by 160 graduating students of SY 2018-2019 of both the BEED and BSED programs. The respondents must satisfy the following criteria for inclusion: (1) Must be officially enrolled in student teaching course and (2) Must be a graduating student.

\section{Sampling Procedure}

Total enumeration was employed in identifying the respondents. Overall this study had 160 respondents composed of 61 BSED and 99 BEED senior students. The study included all COED students deployed for practice teaching for School Year 2018 - 2019.

\section{Data Gathering Instrument}

The research instrument of the study was a researcher-modified one. Some parts of the instrument was adapted from the study of [5] (Leyaley, 2015). The employment readiness questionnaire was modified by adding the first part to gather the profile variable of the respondents. Hence, part 1 contains the profile of the COED seniors. Part II asks about the students' self-assessment on how the various competencies of employment readiness apply to them. The components include: Personal skills, Instructional skills and Management skills. The questionnaire which the respondents were required to complete upon their permission was composed of 30 items on a 5-point Likert scale with the range as follows: $1=$ not skilled, $2=$ least skilled, $3=$ skilled, $4=$ moderately skilled and $5=$ much skilled.

instrument.

A test for validity and reliability was run to check for consistency of measures used in the research

\section{Data Gathering Procedure}

The researchers conducted a survey of all qualified respondents in order to obtain the necessary data for the study. Once the cooperation of the respondents were ensured and with their permission, the questionnaires were administered by means of an assisted interview. The researcher personally interviewed the respondents after which the data gathering instrument were retrieved right after the respondents have completely answered all requisite fields in the questionnaires.

\section{Data Analysis}

The study employed both Descriptive and Inferential statistics for the analysis of the gathered data. Identification of frequencies and measure of central tendency such as the mode was used.

The inferential aspect of data analysis made use of person product moment correlation for continuous data and Spearman's rank order correlation for the variables in categorical nature.

\section{RESULTS AND DISCUSSION} study.

The results of the study are discussed below in accordance with the sequence of the objectives stated in this

As shown in Table I below, the employment readiness in terms of personal skills of the COED seniors resulted in having an aggregate mode of 5 which is interpreted as "much skilled". This implies that the teacher education senior students perceived themselves as showing honesty and integrity, that they are mentally and physically healthy and show punctuality, intelligence and creativity. This only describes that the lessons they learned in the college are highly developed. However they perceived themselves as moderately skilled in terms of being properly groomed at all times. 
Table 1. Employment Readiness of COED Seniors

\section{Personal Skills}

Shows honesty and integrity.

Mentally and physically healthy.

Accepts and performs leadership roles competently in school and 5 community

Shows punctuality.

$\begin{array}{ll} & 5 \\ \text { help to pupils } & 5\end{array}$

Shows concern to pupils'
having difficulties in school.

Properly groomed at all times.

Shows interest in pupils' projects and make adequate assistance to it.

Intelligent and creative.

Indicates confidence that all students should be held to high standard.

Reflects on successes and failures.

Aggregate Mode
Mode

5

5

4

5

5

5

5

5
Interpretation

Much Skilled

Much Skilled

Much Skilled

Much Skilled

Much Skilled

Moderately Skilled

Much Skilled

Much Skilled

Much Skilled

Much Skilled

Much Skilled

\section{Instructional Skills}

Ability to motivate students to lessons and formulate questions 5

Much Skilled

effectively that develop their critical thinking skills.

Selects, prepares and utilizes instructional materials and devices 5 effectively in achieving objectives.

Mastery of subject matter.

Uses other sources for information related to topics aside from books 5

used in discussion.

Ability to provide varied learning experiences.

Conducts reviews of the past lesson before starting a new lesson.

Provides reasonable examples of effective lesson-planning, instructional

strategies, and/or student assessment.

Makes content meaningful to students.

Addresses the multiple and varied needs of students.

Employs learner-- centered strategies.

Aggregate Mode

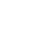

5

5

5

5

\section{Management Skills}

Ability to provide stimulation atmosphere that encourages pupils to 5 raise questions and solutions.

Maintains a well-organized classroom for more conducive learning.

Setting positive class environment.

Equipped with a well-organized plan every day.

Always aware of proper time management.

Facilitates creative flow/transition.

Assumes accountability for classroom environment and cultures.

Persists in offering viable or realistic strategies to deal with classroom management challenges.

Conveys willingness to try multiple strategies or something new when 5 things change or when confronted with challenges.

Displays willingness to adapt classroom management style to meet the 5 particular needs or culture of school.

Aggregate Mode
Much Skilled

Much Skilled

Much Skilled

Much Skilled

Much Skilled

Much Skilled

Much Skilled

Much Skilled

Much Skilled

Much Skilled

Much Skilled

Much Skilled

Much Skilled

Much Skilled

Much Skilled

Much Skilled

Much Skilled

Much Skilled

Much Skilled

Much Skilled

Much Skilled

In terms of the employment readiness component on instructional skills of the COED seniors as shown in Table I above, results show an aggregate mode of 5. This is interpreted as "Much Skilled". This implies that they highly exude in instructional skills. They are much skilled along the mastery of subject matter, ability to provide varied learning experiences, and use other sources of information related to the topic aside from books 
used in the discussion. This further revealed that they are well equipped and have deep understanding of the content, give emphasis on high level of student engagement in classroom discussion.

The employment readiness of the COED seniors in terms of the component on management skills shown in Table I above, resulted of having an aggregate mode of 5 interpreted as much skilled. This describes that the teacher education seniors can manage classroom activities efficiently and can plan and organize well as they highly exude in management skills.

Generally, as shown in Table I, the employment readiness of COED senior students were interpreted as "Much Skilled". All components of employment readiness obtained an aggregate mode of 5 which implies that the respondents are much skilled on the indicators used for each component. The findings in this study is similar to the study of [6] (Adesas, J. Porton T., et al, 2005) on the Perceived Teaching Skills of Prospective BEED fourth year students of ESSU. This evidently shows that COED senior students are ready for employment.

Table 2 below presents the teaching performance of COED seniors. It reflects that $95.6 \%$ or majority of the senior students were excellent in their teaching performance. Only a meagre $1.2 \%$ got a rating of outstanding and another $3.1 \%$ have a rating of very good. From the result, it can be inferred that COED student teachers have developed the necessary skills for teaching and can excellently practice the techniques, skills, and positive attitudes in teaching in preparation for the real world of teaching profession as reflected in their student teaching performance.

Table 2 Student Teaching Performance of COED seniors

\begin{tabular}{llll}
\hline $\begin{array}{l}\text { Final Grade } \\
\text { In Student Teaching }\end{array}$ & Adjectival Rating & Frequency & Percentage \\
\hline 1.0 & Outstanding & 2 & 1.2 \\
$1.1-1.5$ & Excellent & 153 & 95.6 \\
$1.6-2.0$ & Very Good & 5 & 3.1 \\
& Total & 160 & $100 \%$ \\
\hline
\end{tabular}

The result of the study on the relationship between the employment readiness of COED seniors and their student teaching performance is reflected on Table 3 below.

Table 3. Relationship Between Employment Readiness and Student

Teaching Performance of COED Seniors

\begin{tabular}{|c|c|c|c|c|}
\hline \multirow{3}{*}{$\begin{array}{l}\text { Employment } \\
\text { Readiness } \\
\text { Parameters }\end{array}$} & \multicolumn{4}{|c|}{ Teaching Performance (GWA) } \\
\hline & \multicolumn{2}{|c|}{ Correlation Coefficient } & \multicolumn{2}{|c|}{ Level of Significance } \\
\hline & Measure & Interpretation & p-value & Interpretation \\
\hline \multirow[t]{2}{*}{ Personal Skills } & \multirow[t]{2}{*}{$r s=.501$} & Moderate & & \multirow[t]{2}{*}{ Not Significant } \\
\hline & & Correlation & 141 & \\
\hline \multirow{2}{*}{$\begin{array}{l}\text { Instructional } \\
\text { Skills }\end{array}$} & \multirow[t]{2}{*}{$r s=-.393$} & \multirow[t]{2}{*}{ Low Correlation } & & \multirow[t]{2}{*}{ Not Significant } \\
\hline & & & .261 & \\
\hline \multirow{2}{*}{$\begin{array}{l}\text { Management } \\
\text { Skills }\end{array}$} & \multirow[t]{2}{*}{$r s=.922$} & Very High & $* .036$ & \multirow[t]{2}{*}{ Significant } \\
\hline & & Correlation & & \\
\hline
\end{tabular}

*tested at 0.05 level of significance, two-tailed

In examining the relationship of the Employment Readiness Parameters and the Teaching performance of the respondents, Spearman's Rank Order test for Correlation was run. The test revealed a positive, moderate correlation between Personal Skills and the Teaching Performance that was statistically not significant, $(\mathrm{rs}=$ $.501, \mathrm{p}=.141$ ). This proves that the way the student teachers deal with their problems, how they relate with other people, and how they practice their leadership roles moderately but not significantly affect their student teaching performance. This result accepts the null hypothesis that there is no significant relationship between the respondents' employment readiness in terms of personal skills and their student teaching performance.

On the association between Instructional Skills and the Teaching Performance, a negative low correlation between the two variables surfaced, which was also statistically not significant, $(r s=.393, p=.261)$. It can be 
inferred from these findings that the student teachers' skills in utilizing instructional materials and technology, strategies and methodologies, communication skills and content mastery do not significantly affect their student teaching performance. This result also accepts the null hypothesis that there is no significant relationship between the respondents' employment readiness in terms of instructional skills and their student teaching performance.

The test for association between the Management Skills and the Teaching Performance revealed a very high correlation that was statistically significant, $(\mathrm{rs}=.922, \mathrm{p}=.036)$. It is therefore proven that the employment readiness of COED seniors during the school year 2018-2019 in terms of management skills component are significantly related to their student teaching performance. This result therefore rejects the null hypothesis that there is no significant relationship between the respondents' employment readiness in terms of management skills and their student teaching performance. .These findings implies that the teacher education seniors' skills in managing classroom activities, efficient planning and organizing can highly influence their outlook and preparedness towards the teaching profession. This supports the findings of [7] (Shen, J. and Anderson, D.,2020) that teacher's managerial abilities relate positively to students' achievement and that of [8] (George, I.N., et al ,2017) and [9] (Prianto, A., Asmuni, A., Firman \& Maisaroh, S., 2017).prove that self-management approaches can support and enhance teachers' implementation of instructional practices. Hence student teaching curriculum must be enhanced towards improving the management skills of students.

\section{CONCLUSION}

From the results of the study, it can be concluded that :

1. The employment readiness in terms of personal skills of the COED seniors is "much skilled". This implies that the teacher education senior students perceived themselves as showing honesty and integrity, that they are mentally and physically healthy and show punctuality, intelligence and creativity. However they perceived themselves as moderately skilled in terms of being properly groomed at all times.

2. In terms of the employment readiness component on instructional skills, the COED seniors are " much skilled". This implies that they highly exude in instructional skills. They are "much skilled: along the mastery of subject matter, ability to provide varied learning experiences, and use other sources of information related to the topic aside from books used in the discussion.

3. The employment readiness of the COED seniors in terms of the component on management skills is "much skilled". This describes that the teacher education seniors can manage classroom activities efficiently and can plan and organize well as they highly exude in management skills.

4. Generally, the employment readiness of COED senior students were interpreted as "much skilled". All components of employment readiness obtained an aggregate mode of 5 which implies that the respondents are "much skilled" on the indicators used for each component.

5. The student teaching performance of the respondents in terms of their average grade in Student Teaching subject is "excellent". They have developed the necessary skills for teaching and can excellently practice the techniques, skills, and positive attitudes in teaching in preparation for the real world of teaching profession as reflected in their student teaching performance.

6. It is proven that the employment readiness of COED seniors during the school year 2018-2019 in terms of management skills component are significantly related to their student teaching performance. These findings implies that the teacher education seniors' skills in managing classroom activities, efficient planning and organizing can highly influence their outlook and preparedness towards the teaching profession

\section{REFERENCES}

1. en.unesco.org.(2020).The International Task Force on Teachers for Education 2030. Geneva, Switzerland.

2. (teachersforefa.unesco.org). Teachers. "Building peace in the minds fo men and women". United Nations Educational Scientific and Cultural Organization.

3. (Mannathoko, M.C., 2013). Does Teaching Practice Effectively Prepare Student-Teachers to Teach Creative and Performing Arts? The case of Botswana. International Journal of Higher Education 2 (2) p115 DOI: 10.5430/ijhe.v2n2p115

4. (Cresswell, J.W., 2013). Research Design : Qualitative, Quantitative, and Mixed-Method Approaches. 3rd Edition: Sage Publications. University of Michigan.

5. Leyaley, R.V. (2016). The Employability Skills to Teacher Education Graduates of the Kalinga-Apayao State College. International Journal of Scientific Engineering and Research (IJSER), Volume 4 (6) p. 25.

6. Adesas, J. Porton T., et al (2017) Perceived Teaching Skills of Prospective BEED Fourth Year Students of ESSU. The Educator. Volume V(1). p15.

7. Shen, J. and Anderson,D.(2020). The Association between teacher leadership and student achievement: A metaanalysis. Educational Research Review Volume31 (1) p 45. DOI 10.1016/j.edurev.2020.100357. 
8. George, I.N., et al (2017). Effective Classroom Management and Students'Academic Performance in Secondary Schools in Uyo Local Government Area of Akwa Ibom State. Research in Pedagogy, Vol. 7, pp45-56.

9. Prianto, A., Asmuni, A., Firman \& Maisaroh, S. (2017). The effect of academic performance and involvement in the internship program toward life skills and work readiness of university graduates in East Java, Indonesia. International Journal of Business and Management Invention, 6(8), 41-55. 